\title{
Business Intelligence as a Competitive Advantage for SMEs
}

\author{
Teresa Guarda, Manuel Santos, Filipe Pinto, Maria Augusto, and Carlos Silva
}

\begin{abstract}
At present, a company seeking to create competitive advantage, need to understand the data that is generated in the performance of their business. We intend to propose a framework that allows SMEs to take advantage of the information available, to adopt a set of measures supported by Business Intelligence (BI). The adoption of BI in Small and medium enterprises (SMEs) can create the need for organizations to adapt the processes that support systems for decision support, and may have to adapt their systems to the level of databases and applications, providing an additional perspective of information, enabling a more consistent analysis of the data in order to support the process of decision making.
\end{abstract}

Index Terms-Business intelligence, competitive advantage, decision support, SMEs.

\section{INTRODUCTION}

One of the keys of business strategy for creating competitive advantages is understands the data that firms generate in its own business. Information processing has gradually become the basis for achieving competitive advantage. The organization has to believe that have the right information at the right time and available to the right people [1].

The offer of Business Intelligence solutions for SMEs has few alternatives, because the target audience of suppliers of business intelligence solutions remains to be large companies, due to their greater receptiveness to host projects of this nature, and also because of its financial ability.

To realize this article was necessary to analyse the potential of Business Intelligence (BI), their assumptions, scope, limitations, strong points, weaknesses, and its adaptability in the context of SMEs. It is intending to identify obstacles that might impede SMEs from adopting BI.

For a considerable time, large companies have realized the importance of the existing data in their information systems, and began to invest in systems with great analytical skills, particularly in BI. Only recently some SMEs began gathering requirements to receive $\mathrm{BI}$ solutions.

Systems and BI tools have a key role in the process of decision making in organizations. These allow collect, store, access and analyze organizational data in order to support and facilitate decision making [2].

Manuscript received April 21, 2013; revised July 13, 2013

This work is funded by FEDER funds through the Operational Programme for Competitiveness Factors - COMPETE and National Funds through FCT - Foundation for Science and Technology under the Project: FCOMP-01-0124-FEDER-02267, in the context on the PhD in Information Systems and Technologies.

Teresa Guarda is with Universidade do Minho, Portugal (e-mail: tguarda@gmail.com).
Some authors argue that BI cannot be applied to SMEs, and that $\mathrm{BI}$ is a managing process of the exclusive domain of large companies [3]-[4]. However, SMEs are subject to the same circumstances that motivate large organizations to systematize the BI.

The selection of the relevant information is not always consensus and may be different for each organization and in each of its areas. Thus, it is desirable that each area of the organization has a list of needs, in terms of analysis and management, and once selected the necessary information, it shall be made available timely in order to facilitate $\backslash$ assist the process of decision making, either for choosing the best solution, either for the implementation of actions for solving problems at the appropriate time [5].

\section{BACKGROUND}

For Williams, BI "It's not just a technology. It's not just a methodology. It's a powerful new management approach that-when done right-can deliver knowledge, efficiency, better decisions, and profit to almost any organization that uses it" [6].

The complexity of today's business environment requires companies to be agile and proactive in relation to decision-making processes [7], it is necessary to understand the information to track the history of sustainable future events, is this factor that leads many organizations to adopt and BI systems in its business processes [8].

According to Lönnqvist, the BI tools have a number of advantages for businesses, with highlight [9]:

- The reduction of the dispersion of information;

- Greater scope for interaction between users;

- Ease of access to information;

- The information is available in real time;

- Versatility and flexibility in adapting to the reality of the company;

- Useful in the process of decision making.

Globally it can be said that companies intend to obtain and maximize profit through the sale of goods and services. With BI organizations can understand in a systematic sales information and guide trade policies to the specific needs of customers, while still allowing attract new customers and retain old customers with value-added products [10].

According to Guarda [11], BI bridges between different systems and users wishing to access information, providing an environment that facilitates access to information needed for day to day activities, allowing analyze the business performance. 
With BI organizations can integrate powerful tools, analysis, standardized reporting, monitoring system with various metrics, data integration, among other features, within a service-oriented architecture [12], [13], essential for a good business management to guide managers in strategic direction for quality information, with the establishment of standards and procedures to ensure compliance with the objectives

The techniques of analysis and visualization can detect evolutionary data previously ignored. Finally, the strategic measures could provide an alignment with tactical initiatives, by setting strict goals and objectives to be achieved in each moment, allowing control over the same simplified and more efficient correction of deviations.

The ease of the historical analysis is facilitated if the organization has a repository of historical data, both internal and external source, enabling exploratory analyses using BI techniques [14].

The combination of historical data with BI tools allow SMEs to take strategic decisions relevant through exploratory techniques of large volumes of data potentiating analyses of unknown patterns, which is an important advantage in understanding the business processes.

Organizations should adopt a strategic and active behavior, adjusting supply to its customers, exploring a more competitive pricing model, eventually replacing the current market for new markets, and becoming more competitive compared to its competitors [15].

Generally organizations look for information regarding the analysis of less favorable situations, this analysis is a reactive action to a negative or adverse situation. In a proactive management perspective, if the results are positive, organizations must continue to develop actions to leverage and optimize the obtained results. Reactive organizations, wears all its energy and all the resources in the inversion of negative results, at the expense of improving their skills and explore opportunities. Without these skills and approaches to business, organizations fail to evaluate the course of business [16].

The organization must decide whether to have a reactive behavior or pro-active behavior. A proactive organization is focused on meet the opportunities and prepared to anticipate possible failures [17].

On the business environment constantly changing, it can be verified that the requirements at the level of information technologies, market challenges and business pressures faced by SMEs are not much different than those faced by large companies. Large companies have harvested over time the benefits of BI systems, since they can implement and maintain BI solutions.

At present, the volume of data that companies create and store is increasing. There are several data sources: customers, suppliers, business partners, market research, among others. The management of large volumes of data and transforming it into useful information is the challenge posed to SMEs. A viable alternative for SMEs could be choose the solutions Software-as-a-Service (SaaS), which enables companies to strengthen with systems and information technologies current, as well as improve the quality of their information systems, giving a competitive advantage to the company
[18].

Generally deprecated software applications used by SMEs will prove to be an enabler for radical change, since SMEs are increasingly pressured due to evolving markets and technologies [19]. Thus, BI systems seem to be the right choice for organizations, allowing enjoying the advances in information technologies (IT), deploy software applications that rather than adjust business processes in accordance with the restrictions of software, allowing the integration of information flows from clients and suppliers, and redesign and formalize business processes.

It is not guaranteed that a BI system will generate a return on investment because not every business has been successful with BI solutions. But an adequate and integrated $\mathrm{BI}$, can create the competitive advantage necessary for SMEs be successful.

Is questioned what type of BI solution should adopt an SME to meet its business needs.

Once identified business processes must be identified stakeholders key and their roles should be defined the functional requirements and define the information needed for reporting, analysis, and presentation delivery.

SMEs that have adopted BI system quickly realized that they can compete more effectively in the marketplace, with additional information about their customers, these patterns and requirements, as well as a more efficient financial management.

\section{FRAMEWORK PROPOSAL}

The framework can be an efficient method to validate the requirements of a project, as a way to detect any faults and discrepancies against the requirements of the project. In case $\mathrm{BI}$, the framework allows evaluating the capabilities of this technology through to data access and analysis that can assist in organizations decision making [6].

We intended to develop a framework that exemplify and clarify the applicability of the BI as a driving force for SMEs, bridging the gap between theoretical knowledge and practical use of a tool for decision support. The exploration of the historical data of customers with BI tools will facilitate decision-making and planning strategies through the use of techniques for extraction, processing and visualization of data and exploitation mechanisms of large volumes of data, enhancing the analysis of unknown patterns, which constitutes an important advantage in understanding the business processes [20]-[21].

The proposed framework is structured in four phases, as depicted in Fig. 1:

- Planning;

- Technology;

- Intelligence;

- Dissemination.

The first phase is planning. SMEs face similar challenges in terms of BI to larger organizations. It is necessary to define what data is needed, which will form the basis of BI. In the next phase, the technology integrates the BI systems software that includes data mining, data analysis, scorecards and 
dashboards. Currently, the providers of BI tools have some BI tools priced within the reach of SMEs, some of these being available online. The next phase, intelligence, must be taken into consideration that one of the most important aspects of a BI project is determining what needs to be evaluated, and how to be assessed. Thus, you should define the critical success factors of the business, and are determined for each of these metrics appropriate for measuring $\backslash$ assess what is running and creating the appropriate alerts. These metrics will support the architecture of the BI solution. SMEs have the advantage hold a greater ease in defining the metrics, since they have a comprehensive and detailed knowledge of the business, and the downside of their managers are not accustomed to managing or being managed by metrics. In the last phase, the dissemination should in principle be the simplest process, unless the previous phases have not been successfully performed. At this stage it is essential that users of the system known to interpret the test results obtained.

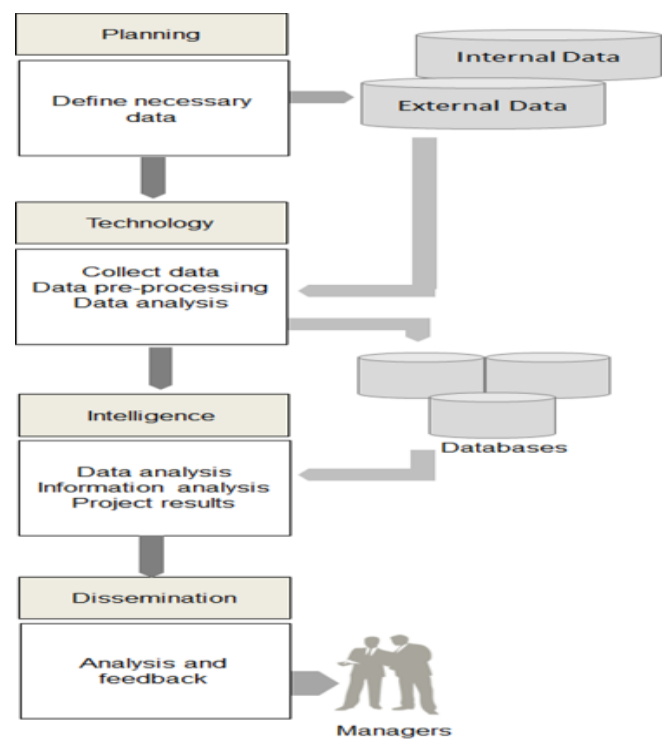

Fig. 1. Framework for BI implementation.

\section{CONCLUSION}

Due to the increased volume of data in the organization, the BI has become essential for any company, whatever its size, and is essential for decision making.

For SMEs it is essential to align its strategy for growth supported on the appropriate management tools. The use of software applications obsolete by companies could be the booster for radical change that SMEs need to face the changing markets and technologies.

Due to the size and specific characteristics, negotiation power of SMEs is limited. The choice of a suitable BI system is strategic, allowing companies to take advantage of advances in technology. Despite the advantages of applying techniques of BI in organizations in general, there are few alternatives aimed at SMEs. A viable alternative for SMEs could be choose the solutions Software-as-a-Service (SaaS).

\section{REFERENCES}

[1] A. Palmer and B. Hartley, The Business and Marketing Environment, 3rd ed., London: McGraw-Hill, 2000.
[2] D. A. Aaker, V. Kumar, and G. S. D. E. R. Leone, Marketing Research, 10th Edition, Wiley.com, 2009.

[3] R. Legendre, "Es la inteligencia de negocio aplicable a las Pymes?" Puzzle: Revista Hispana de la Inteligencia Competitiva, vol. 4, 2005.

[4] G. Gangadharan and S. N. Swami, "Business intelligence systems: design and implementation strategies," in Proc. 26th International Conference on Information Technology Interfaces, 2004.

[5] Y. Santos and I. Ramos, Business Intelligence: Tecnologias da informação na gestão de conhecimento, FCA, 2006.

[6] S. Williams and N. Williams, The Profit Impact of Business Intelligence, Morgan Kaufmann, 2010.

[7] P. Bocij, A. Greasley, and S. Hickie, "Business information systems: Technology, development and management," Ft Press, 2009.

[8] O. Marjanovic, "The next stage of operational business intelligence: Creating new challenges for business process management," in Proc. 40th Annual Hawaii International Conference on System Sciences, HICSS, 2007.

[9] A. Lönnqvist and V. Pirttimäki, "The measurement of business intelligence," Information Systems Management, pp. 32-40, 2006.

[10] A. Green, "Business information--a natural path to business intelligence: knowing what to capture," VINE, vol. 37, pp. 18-23, 2007.

[11] T. Guarda, M. F. Santos, F. Pinto, C. Silva, M. Augusto, and J. Lourenço, "Pervasive business intelligence: a marketing intelligence framework proposal," in Proc. 3rd International Conference on Business, Economics and Tourism Management - CBETM, Hong-Kong, China, 2012.

[12] W. W. Eckerson, Performance Dashboards: Measuring, Monitoring, and Managing Your Business, Wiley, 2010.

[13] J. Ranjan, "Business justification with business intelligence," Vine, pp. 461-475, 2008.

[14] U. Sekaran, Research Methods for Business, John Wiley \& Sons, 2006.

[15] M. Reeves and M. Deimler, "Strategies for winning in the current and post-recession environment," Strategy and Leadership, vol. 37, pp. $10-17,2009$.

[16] C. Mast, "Internal communication and leadership," Public Relations Research, 2008.

[17] M. W. Peng, W. Sun, and X. Liu, Global Strategy, Thomson/South-Western, 2006.

[18] M. Tvrdíková, "Increasing the competitive potential of small and medium firms by IT," Information Technology for Practice, pp. 183-188, 2012.

[19] S. Lee, G. Park, B. Yoon, and J. Park, "Open innovation in SMEs-An intermediated network model," Research Policy, vol. 39, pp. 290-300, 2010.

[20] A. Nicolaou, "10 Alignment of AIS with Business Intelligence Requirements," Business Intelligence Techniques: A Perspective from Accounting and Finance, pp. 167, 2003.

[21] M. Castellanos, F. Casati, U. Dayal, and M. C. Shan, "Comprehensive and automated approach to intelligent business processes execution analysis," Distributed and Parallel Databases, vol. 16, pp. 239-273, 2004.

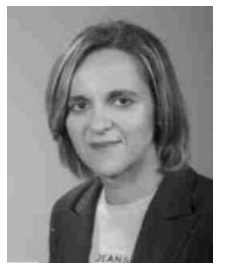

Teresa Guarda was born in Leiria, Portugal in 1966. She is a professor of management information systems, project management, project coordination, and technical design and interpretation projects in ISLA Superior Institute of Leiria, Portugal. Graduate in informatics management by Isla -Superior Institute of Lisbon (1990), and master in systems and information technology by University of Coimbra (1999). At present, she is a PhD student in the Department of Information Systems at University of Minho, Guimarães, Portugal. Her research interests include pervasive business intelligence, marketing intelligence, data mining, process mining and knowledge discovery. Dr. Guarda is a member of Centro Algoritimi.

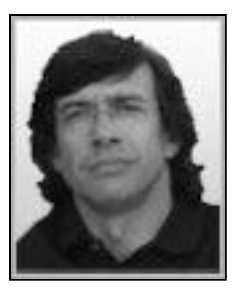

Manuel Filipe Santos received his $\mathrm{Ph} . \mathrm{D}$. in Computer Science (Artificial Intelligence) from the University of Minho (UMinho), Portugal, in 2000. He is an associate professor at the Department of Information Systems, UMinho, teaching undergraduate and graduate classes of Business Intelligence and Decision Support Systems. Also researcher at the Business Intelligence Group (big.dsi.uminho.pt) of the R\&D Algoritmi Centre, with the current research interests: Business Intelligence and Decision Support Systems; Data Mining and Machine Learning (Learning Classifier Systems); Grid Data Mining. He participated in various R\&D projects, being 
Principal Investigator of 2 projects, namely: Intcare - Intelligent Decision Support System for Intensive Care Medicine, Gridclass - Learning Classifier Systems for Grid Data Mining. He supervised $13 \mathrm{MSc}$ theses and $2 \mathrm{PhD}$ theses. Currently he is supervising $9 \mathrm{PhD}$ students. Co-organized the EPIA 2007 - 13th Portuguese Conference on Artificial Intelligence. Reviewer of several conferences (e.g. AAMAS, EPIA, ICEIS, ICAART,MEDI) and journals (e.g. European Journal of Operational Research, Intelligent Decision Making Support Systems); Co-organizer of the Knowledge Discovery and Business Intelligence - KDBI 2009 and 2011 thematic track of EPIA; WISA/CISTI 2011 and Intelligent Systems/ESM 2011.

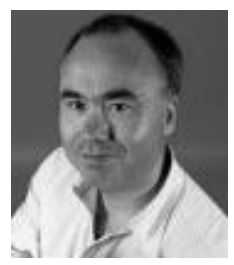

Filipe Mota Pinto received his Ph.D. in Database Marketing and MSc in Information Systems, he held positions at Repsol and Cepsa in Portuguese (Responsible area cards). Currently integrates the director of the Technological Park of Óbidos (representative IPL) and is a lecturer in the Department of Computer Engineering at ESTG IPL. It is also Coordinator of Graduate Web Marketing. Research field: Computer and Information Science (Database Marketing, Ontologies and Data mining)

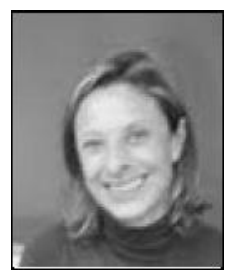

Maria Augusto was born in Leiria in 1960, she got the bachelor in Secretariat Direction by Ecole Etienne Marcel, Paris (1983), she postgraduates in Finnce by School of Technology and Management of Leiria (2010), Postgraduate Financial Management and Audit Companies by APEU Faculty of Economics of Coimbra (2012), finishing the course of enterprises management in ISLA - Superior Institute of Leiria. She is administrator and project manager.

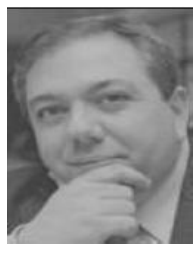

Carlos Silva was born in Leiria in 1970, he is a Ph.D. student in Management (Strategy) since 2009 at Universidade Aberta, he got master in International Economics (1996) by ISEG (Lisbon, Portugal) and graduate in International Relations (Economic) in 1993 by Lusiada University (Lisbon). He is the dean of ISLA - Leiria (higher education institute), teacher of Organizations Management and Marketing and the Coordinator of the Management department. Dr. Silva is a member of the Wade World Trade, a member of Talentus and has is also a member of OSMTH International. 